\title{
BRITISH SOCIETY OF ANIMAL PRODUCTION, 1944-54
}

$\mathrm{F}^{\mathrm{o}}$ OR many years before the Second World War it had become recognized by scientific workers and practical animal husbandmen that the marginal territory over which both groups move could not be reasonably developed unless means were found of exchanging ideas and experience and of combining them in a scientific approach to problems of animal production. The position in Great Britain differed sufficiently from those in other countries to limit adoption here of precisely the same patterns of organization for this purpose as had been set up overseas; the livestock industries were under less direct governmental and administrative control than in parts of Europe, where bodies with similar aims were in being or contemplated; in the United States the American Society of Animal Production was well established, with a large membership, mainly of scientific workers and advisers, and a long record of valuable published contributions; and, moreover, university departments and research institutes in Great Britain were not so specialized or so opulent, and yet the art and practice of stock husbandry was traditionally on a high plane of achievement.

Again, research workers were more and more tending to present their findings in journals and at meetings so specialized that they were relatively inaccessible to the practical man. Almost as an immediate result of this sectionalization of interests, it was increasingly more difficult for specialists in cognate fields to come together to discuss the mutual inter-relationships of their work, and even more so for the practical stockman to meet the scientist on common ground.

In 1939 the time appeared ripe to form a British organization which might meet local needs and ultimately link up with the European Association then being instituted to foster the wider interests of the existing national societies; and a small group, led by Dr. John Hammond, began to consult with breeders, research workers and advisory officers with this objective. The outbreak of the War imposed delay; but the informal group kept together and by the end of 1943 judged that their ideas could be made more widely known. It was realized that no large membership could be expected for some time, but the response was immediate and enthusiastic. The first meeting was held early in 1944, a constitution adopted, and with Dr. Hammond as its first president, the new British Society of Animal Production began to develop four broad ways of policy.

The first related to reviews of the main sections of the livestock industry, and was in a sense introductory or short-term. By 1944 not only had British animal production been greatly disturbed, with the main emphasis on milk, but also it was clear that difficult problems would appear in any post-war period of readjustment. It is interesting to note from the reports of those earlier meetings, at which the sheep, meat and pig situations were examined, how well the position which was to arise in the late 1940's and these early 1950's was then foreshadowed. That this could be so was largely due to the course taken towards the second line of policy : the founders aimed at securing roughly equal proportions of membership from the scientific, the advisory and the practical fields. It is noteworthy that such a balance in the roll of members still exists and that each field contributes freely and effectively to the business and vigour of the Society.

A third line of policy was to hold, if possible, two meetings a year: one in London to receive formal papers and discussion; and the second in the Provinces, primarily to provide opportunities of visiting research centres, to view practical developments in animal husbandry, and to consider, on the ground, the livestock industries of the area. This mode of operation still continues, enabling the basic aims of the Society to be firmly expressed. The fourth line of policy was to publish records of the proceedings of the Society in the hope that ultimately the depth and breadth of the volume of progress in the field of scientific animal production in Great Britain would sustain the quality of contributions to a substantial journal. The publication of the "Proceedings" of the Society for 1954 gives an opportunity for reviewing progress made by the Society in the first ten years of its life*.

From the earlier form of reports of meetings, with their records of discussions on the formal papers presented, and accounts of local stock industries and husbandry methods, the first outward development was made in the "Proceedings" for 1952. In that year the serious outbreak of foot-and-mouth disease eliminated the autumn 'local' meeting, so that with no report on it to publish, space was given to an account of the activities of the European Association for Animal Production (to which the Society had attained working membership) and, more significantly in relation to policy, to two contributions on progeny testing - the first being a valuable review of principles and methods by Johansson and Robertson, and the second a critical assessment by Mason of the system and results of bull-progeny testing in Denmark. These papers not only formed an introduction to the central theme of the eighteenth meeting held in 1953, but also added materially to the status of the Society's publications as an essential source of reference to work in the general field.

The 1953 "Proceedings". record a symposium on progeny testing in dairy cattle, pigs, sheep and pouliry, together with three special papers on then current research in Scotland, involving feeding experiments with twin cattle, pig research at the Rowett Research Institute, and work by $\mathrm{K}$. L. Blaxter on the relationships of diet to muscular disease in calves.

The next step in policy was taken in 1954 when, at the spring meeting, sixteen papers were given as accounts of work in progress. Compared with the offerings in previous "Proceedings", they form not an orderly sequence of courses but a mixed dish the components of which vary greatly in substance, digestibility and net value, yet which as a whole is appetizing and satisfying as representative of the products becoming available from the further scientific exploration of animal production in Great Britain. Some contributions are given in full, and others only by summary. They range from studies on techniques of weighing grazing animals and the results of winter grazing methods, to comparisons of

* Proceedings of the British Society of Animal Production, 1954. Pp. 116. (Dalkeith: Scottish County Press, 1954.) 158. 
breeds and crosses for beef production; from examination of the seasonal changes in management in relation to milk yields to the assessment of progeny test results and to the effects of inbreeding on performance in dairy cattle; from investigations on nutritional levels in late pregnancy, through others on meat quality and on body size in reciprocal crosses, to analyses of the factors of flock size and flock duration in the population genetics of sheep. There are also reports of work on the use of partial records in poultry selection, on the experimental shortening of the generation interval in rabbits by gonadotrophin treatment, and preliminary accounts of comparisons of different sources of vitamins $A$ and $D$ in relation to the fattening of pigs and of $X$-ray studies on the structure and variation of the vertebral column in the Welsh breed of pigs.

The "Proceedings" are well edited, and appear in pleasing and convenient format : their diffuse contents may suggest that in this step of policy the riser is too high too early in the stairway to the platform of a British Journal of Animal Production. On the other hand, the tread seems sound, and it may well be that the Society can now move up and on to achieve this particular aim, without side-tracking its other aims, of which the study of local methods and practices of animal production is by no means the least valuable and of which all record has been somewhat regrettably omitted for 1953 and 1954 .

J. E. Nichols

\section{BERLIN ACADEMY OF SCIENCES}

'HE first 'annual meeting' of the Deutsche Academie der Wissenschaften zu Berlin to be held since the War took place during March 28April 2. Until 1939, there had been an annual celebration of the first president of the Academy, G. W. Leibniz. The present meeting was a revival of this tradition. Some four hundred and seventy scientists from Eastern Germany and some eighty scientists from other countries, including Western Germany, took part in the meetings.

The opening session was held in the Grosser Festsaal im Haus der Ministerien and was addressed by the president of the Academy, Prof. W. Friedrich, well known as the co-discoverer, with von Laue and Knipping, of the diffraction of X-rays by crystals. Government representatives present included the president of the Volkskammer, Dr. Dieckmann, and the Prime Minister, Otto Grotewohl. After Dr. Friedrich had spoken, each of the secretaries of the five sections of the Academy reported on his own section. Last year a considerable reorganization of the Academy took place so that the subjects are re-grouped in the following way: (1) mathematics, physics, engineering ; (2) chemistry, geology, biology; (3) medicine ; (4) language, literature and art; (5) philosophy, history, law, economics. (The inclusion of non-natural science subjects within the purview of the Academy follows a common Continental custom of using the word science in the meaning of 'scientas'.) The secretaries' reports all showed a very considerable development of the work done by the various institutions and laid stress on the need for ensuring a proper application to industry of the results of scientific research. The present secretaries of the sections are, respectively, Profs. Rompe, Noack, Lohmann, Frings and Unverzagt. The second full session was addressed by Prof. Kurt Mothes on "The Roots of Plants-a Chemical Factory of a Particular Kind", and by Prof. Wolfgang Steinitz, vice-president of the Academy, on "Songs and Fables as Expressions of the Spirit of a People". Then followed two and a half days of conferences on specialized subjects. These included "Physics and Chemistry of Crystals", "Metallurgy of Iron", "Radio-astronomy", "Fibres from Synthetic High Polymers", "Results and Problems of Biochemical Research", "Questions concerning Cancer Research and Treatment", "Dialect Study", "Songs, Fables, Proverbs and Sayings, as expressions of the Spirit of a People". There were also lectures by Prof. Gordon Childe (London) and Prof. Hans Jürgen Eggers (Hamburg) in the Institute for Pre- and Early-History, and by Prof. Johannes Straub (Bonn) in the Commission for Spätantike Religionsgeschichte. Visits were arranged for all the visitors to the laboratories and institutions in which they were interested. An informal reception was arranged on the first evening and a dinner party in the great hall in the Haus der Ministerien at the conclusion of the meetings. A two-day excursion to Weimar, famous for its associations with poets, was arranged for those who had time to go.

Certain general impressions may be worth recording. The scientific institutions and those who work in them are flourishing; the material means both in terms of research facilities and salaries are good. There is a widespread desire for more contact with scientists in other countries, and a wish to be able to attend international conferences more easily than is possible at present. The publications of the Akademie Verlag include a considerable number of translations of important modern Soviet books, and for those who cannot read Russian the German Academy is likely to be of great service through those translations. Finally, it should be said that the friendliness and hospitality shown by our hosts were all that could be desired.

W. A. Wooster

\section{NATIONAL SCIENCE FOUND- ATION, WASHINGTON, D.C. REPORT FOR 1953-54}

$T$

HE fourth annual report* of the National Science Foundation, Washington, D.C., covers the year ended June 30, 1954, and includes, besides the report of the director, Dr. A. T. Waterman, a foreword by Chester J. Barnard, chairman of the National Science Board, and appendixes listing the personnel of the Board and its advisory panels and committees and the basic research grants made during the year, as well as a complete list of individuals awarded fellowships in 1954. Mr. Barnard emphasizes in his foreword that the central task of the Foundation is the promotion or cultivation of science in the United States, and in this connexion notes the importance of incentives for the pursuit of scientific careers. A deep, personal and indefatigable interest in scientific discovery is the primary and indispensable incentive; but relative freedom, adequate remuneration and public esteem are also important, and lavish and indiscriminate expenditure will not counterbalance conditions which discourage initiative, imagination

* National Science Foundation. Fourth Annual Report for the Fiscal Year ending June 30,1954 . Pp. $1 \mathrm{x}+138+4$ plates. (Wash-
ington, D.C. : Government Printing Office, 1954.) 50 cents. 